\title{
Maar my voete wil nou sing
}

C J A Vos

(Universiteit van Pretoria)

\section{ABSTRACT}

\section{But my feet wish to sing}

In this article the author takes a closer look at biblical erotica through the eyes of poetry on the one hand and contemporary Afrikaans poetry on the other. By way of conveying some thoughts on texts in Song of Songs (along with other assorted scriptural texts) the ideas regarding sexuality encountered therein are made to converse with a careful selection of a number of Afrikaans poems to express in homiletical fashion something about the wonder and mystery of this greatest of Heaven's gifts bestowed upon the human condition - the divine spark.

\section{INLEIDING}

In Laurika Rauch se lied, my ou tante Koba, weerklink die refrein:

Maar my voete wil nou dans

en my lippe wil nou sing.

Dis ' $n$ lied vol heerlikhede. Só aards en menslik. Ek wil die twee reëls soos sterre op die water ' $n$ bietjie skommel.

Maar my voete wil nou sing

en my lippe wil nou soen.

Dit is die hartklop van erotiek: voete wat wil sing en lippe wat wil soen.

In die Rutverhaal gee skoonma Naomi aan Rut die raad om in die nag na die dorsvloer toe te gaan. Dáár dors Boas gars op die dorsvloer. ' $n$ Mens snap dadelik waarom dit eintlik gaan as Naomi vir Rut sê: "Was jou, maak jou mooi en trek jou netjies aan... Wanneer hy gaan slaap, sorg dat jy weet waar hy gaan lê. Dan gaan jy soontoe en kruip by sy voete in. Hy sal jou dan sê wat jy moet doen” (Rut 3:3-4). Nadat Boas heerlik geëet en gedrink het, het hy langs die mied gaan lê. Die spanning bou op. Rut laat ook nie op haar wag nie, maar kom stilletjies (erotiek kom gewoonlik stilletjies), maak sy voete oop en by voete in (Rut 3:7). Hierdie oopmaak van Boas se voete het duidelike erotiese ondertone. Maar my voete wil nou sing. 
In hierdie bydrae gaan dit om die goddelike vonk van die erotiek in die poësie. Ek kyk na 'n paar Hoogliedgedigte en ander verse. Voordat ek my oë na die Hoogliedgedigte, en ander gedigte laat gaan, gee ek eers aandag aan die begrip erotiek.

Erotiek gaan in ' $\mathrm{n}$ vol menslike en verbeeldingryke konteks met seksualiteit om. Die mens se libido is vir sy erotiese bewussyn noodsaaklik, maar nie bepalend nie. Erotiek gee ook betekenis en gestalte aan die mens se estetiese en religieuse handelinge. Die seksuele is wesenlik deel van die menslike bestaan.

In Hooglied word die liefde ' $n$ krankheid genoem. Dit maak die hele mens na siel en gees siek, liefdessiek. Die erotiek is ' $n$ skeppende krag wat die hele menslike lewe omspan. Gedagtes, woorde, dade, verhoudinge is alles eroties deurdrenk.

In taal kry erotiek lewe en verstaan. Taal is immers palingglad (Weideman 1998:111). 'n Mens sou ook kon sê: erotiek vibreer in taaldrade - semantiek, sintaksis, fonologie en morfologie (Gouws 1995:146). In Barthes (1978:73) se woorde: "Language is a skin; I rub my language against the other. It is as if I had words instead of fingers, or fingers at the tip of my words. My language trembles with desire".

TT Cloete (1992:4) dig soos volg oor die inskrywende aard van taal:

Dit grif in my ' $\mathrm{n}$ diepe plesier

en ' $n$ ver oorspronklike emosie

om met ' $n$ stukkie vuurhoutjie in die loodpapier

van 'n sigaretdosie

te skryf, nie óp nie maar in.

In die boombas of bamboesvlies is geskryf

deur mense in ' $n$ vroeë begin,

in is deur die ou kleitabletters

in voortye geskryf in petrogliewe letters.

In in die taal se meegewende lyf

word deur die digter diep gevoelig ingegryf.

Antjie Krog (2000:65) se gedig, digter wordende, handel oor die dig- en skeppingsproses: 
om op 'n oggend wakker te word binne-in klank

met vokaal en klinker en diftong as voelspriet

om met aarselende sorg die effensste roerings

van lig en verlies in klank te kalibreer

om jouself meteens gekniel te vind

bo-oor die hoorbaar kloppende wand

van 'n woord -soekend na daardie presiese

moment wat ' $n$ versreël volloop in klank

wanneer die betekenis van ' $n$ woord swig,

begin gly en hom eindelik oorgee aan geluid

van dan af smag die bloed na die inkantasie

van taal - die enigste waarheid staan gevèl in klank

die digter dig met haar tong

sy haal asem - ja, diep uit haar oor

In poësie kom die skeppende en verbeeldingskrag navore. In die ritme en golwinge van poësie is erotiek aanwesig

Daar is ' $n$ grondige verskil tussen erotiek en pornografie. Pornografie gedy op verdrukking en bedekking. Daarom is perversie die erotiek van haat, pornografie (Gouws 1995:147; Haag en Elliger 1999:112-113, 208 -209).

Van alle soorte tekste is erotiese tekste straks die soort teks waarvan die meeste mense ondervinding het - van gedeeltes uit die Bybel en die Koran, verby die kleuterryme en toiletgrafitti tot by van die mooiste gedigte in Afrikaans (De Lange en Krog 1998:XIII).

Ek konsenteer op Hooglied as interteks vir gedigte en sluit af met ' $n$ ' $n$ liefdesbrief.

Die vuurslag van Hooglied is nie net poëties van waarde nie, maar open ook perspektiewe tot die verstaanshorison van Hooglied. Michel Foucault (1981) het duidelik uitgewys dat die geskiedenis van seksualiteit ' $n$ geskiedenis van onderdrukking is.

Dit het Hooglied ook te beurt geval (oor Hooglied, vgl Gerleman 1965; Kroeze 1970; Haag en Elliger 1999:119-125; Davis 2000; Schwienhorst-Schönberger 2004). Hooglied is vir eeue lank versluier en vergeestelik. Die kerkvaders het op allerlei vindingryke maniere Hooglied van die lyf vervreem. 'n Mens het soms skuldig 
gevoel as jy self sien wat in Hooglied staan. Maar om die liggaam in te hok, is die gees van allegorie aangeblaas. Die allegorie beoog om ' $n$ diepere sin in ' $n$ teks te onthul. Die vertrekpunt van die allegoriese eksegese is dat die verhouding tussen God en sy volk voorgestel word met die beeld van 'n huweliks-verhouding. In die Christelike allegorie is óf die gemeente (die kerk as mistieke liggaam van Christus) óf die gelowige die bruid van Christus. Maria is ook by due uitleg van Hooglied betrek. Die jongvrou uit Hooglied word as " $n$ voorbeeld van Maagdelike lewe (!) met Maria, "die moeder van God" gelykgestel. Hieronymus "bewys" hierdie opvatting met Hooglied 4:12 waar die "geslote tuin", die "geslote bron" en die "verseëlde fontein" die maagdelikheid van Maria vóór en ná die geboorte van haar Seun aandui.

Die jongman is tipe van Christus en die jongvrou die Bruid van Christus, die gemeente. Daar bestaan talle variasies van die allegoriese verklaring. Dit gaan nie in Hooglied om die liefde tussen ' $n$ bruid en ' $n$ bruidegom nie, maar om die bruidegom Christus en sy bruid, die kerk. In só 'n verstaan is daar nie plek vir erotiek nie. Die twee borste, het van die kerkvaders geleer, is nie twee vroulike borste nie, maar die nagmaal en doop. Hoe heerlik is die nagmaal en die doop tog nie!

Benewens die allegoriese uitleg van Hooglied is daar ook die tipologiese verklaring van Hooglied. Die tipologiese verklaring van Hooglied bestaan daarin dat in die Hooglied lewende, historiese persone optree.

Tekste uit die omringende Oosterse wêreld en die verkwikkende liefdeborreling van Hooglied het ander gedagtes losgemaak. In die "papyrus Harris”, afkomstig van die graftombe van Ramses 11 in Thebe kom ' $n$ belangrike versameling Egiptiese liefdesliedere voor. Uit Thebe is daar ook nog die "papyrus Chester Beatty 1" met sy "sewe sange oor die groot vreugde van die hart" en sy "drie liefdeswense". Hier gaan dit om die viering van die liggaamlikheid van liefde. Hier bloei die erotiek.

In Loflied 1 (Vos 1999:3) handel dit oor die verlange na en verwagting van die geliefde se koms. Vir die aankoms is die tafel gedek met liefde. 
Sterre ruik na bloeisels jasmyn, die maan poeier ' $n$ pad se plooie, 'n droom drup olie, ryk aan geur:

voetstappe is ligte tromslae en uit paddas se kele dreun kwaakvars basstemme.

My ore soek na jou tong, ' $n$ brug waarop vreugde dans, 'n singende klok, klanke wat my hart laat bokspring.

Op ons tafel lê ritsels kant, groenvytjies se soet vingers wink vir rosynekoeke, appels, wyn: ons tafel gedek met liefde.

In Loflied 111 (Vos 1999:5) word die die koms van die geliefde visueel geteken. Haar liggaam in sy volheid word besing. Dit is sy in haar liggaamlikheid wat dit hemel op aarde maak.

Hoe sierlik jou liefdeshuppel, jou hare is purpermantel, jou kop 'n paleis waar wyses woon, jou oë fonteine wat murmel.

Die goue toring van jou nek waaroor duisend sonne lek, slank begeerlik - jou lyf 'n palmboom vol grypsoet trosse.

Uit jou borste vloei melk en heuning, my lief, jou lippe plooi skaam as ek by jou poort aanklop. 
By jou verhemel alles op aarde.

In die gedig, Ingang, word die seksuele as uitdrukking van die erotiese gevier.

Wie mag by haar aanklop

en in haar heiligdom

tot verrukking kom?

Dié man wie se hande

sagkens kan troetel

en wie se hart lig galop,

wat met sy tong rats

die liefde kan aanhits.

Só ' $n$ man sal by haar

' $n$ soet inval ervaar.

Haar poort swaai wyd oop

en haar geliefde loop

suutjies lighoofdig

na haar wyplek

waar hy klam en naak

' $n$ mondvol hemel smaak.

Maar my voete wil nou sing, daarom skryf 'n e-pos gedig vir jou.

Allerliefste, ek stuur vir jou 'n e-pos duif want niemand sal 'n skouduif se penveer pluk nie. My vingers swiep windvlerke oor die sleutelbord, kleur die rekenaar se toetse met liefderyke woorde wat op my wit skerm hoog en laag vlieg.

Kyk, my duif kom op en my duif gaan onder

op die elektroniese stroombane

en waar hy vlieg daar glinster my boodskap 
en jou oë word groen:

jy moet sien altyd weet liefste van my liefde

soos van vlerke waarmee ons nie kan vlieg nie.

Jy moet sien my liefde stryk

skitterend op jou hartskerm neer.

Maar my voete wil nou sing

al sou ons sleepvoet en doekvoet loop

hande krom soos haakdoringbos

al het die wind die gousblom gestroop

al het die jare ons uitoorlê

sal ek jou heel my lewe lank bly liefhê

al sou ons sleepvoet en doekvoet loop (Weideman 1997:57).

Maar my voete wil nou sing, want erotiek is die goddelike vonk wat die liefde laat vlam. Liefde is die grootste.

\section{Literatuurverwysings}

Barthes, R 1978. A lover's discourse: fragments. Hill \& Wang: New York.

Breytenbach, B (Jan Blom). 1981 (Tweede uitgawe, eerste druk). Lotus. Taurus: Emmarentia.

Cloete, T T 1992. Met die aarde praat. Tafelberg: Kaapstad.

Davis, E E 2000. Proverbs, Ecclesiastes, and the Song of Songs. Westminster John Knox Press: Louisville, Kentucky.

De Lange, J en Krog, A 1998. Die dye trek die dye aan. Kaapstad: Human \& Rousseau, Tafelberg.

Foucault, M 1981. The history of sexuality. Harmondsworth: Penguin.

Gerleman, G 1965. Ruth. Das Hohelied. Neukirchener-Verlag: NeukirchenVluyn.

Gouws, T 1995. Naspel in: Gouws, T (samesteller), BLOUDRUK erotiese verhale. Gouws, T (samesteller). Pretoria: J P van der Walt, 142-149.

Haag, H en Elliger, K 1999 (Tweede uitgawe). Zur Liebe befreit. Sexualität in der Bibel und heute. Düsseldorf: Benziger. 
Kroeze, J H 1970. Bybel en seks. Braamfontein: Boekhandel de Jong.

Krog, A 2000. KLEUR KOM NOOIT ALLEEN NIE. Kaapstad: Kwela Boeke.

Schwienhorst-Schönberger, L 2004. Das Hohelied, in: Zenger, E (Hg.) Einleitung in das Alte Testament (5de uitgawe). Stuttgart: Verlag W. Kohlhammer.

Vos, C 1999. Vuurtong. Pretoria: Benedic.

Weideman, G 1997. ' $n$ Staning onder sterre. Kaapstad: Tafelberg

-, 1998. Pella lê 'n kruistog vêr. 'n Keuse uit sy poësie 1966-1987. Kaapstad:Tafelberg. 